\title{
A EPISTEMOLOGIA DE MATURANA
}

\section{The epistemology of Maturana}

\section{Marco Antonio Moreira ${ }^{1}$}

Resumo: Diferentemente dos epistemólogos mais conhecidos no Ensino de Ciências, geralmente oriundos das ciências físicas e predominantemente racionalistas, Maturana vem das ciências biológicas e procura explicar o conhecer explicando o conhecedor e tomando como ponto de partida a experiência do observador e o observar. Esse observador não pode distinguir, na experiência, entre ilusão e percepção, mas pode gerar explicações da experiência que são reformulações da experiência. As explicações científicas, por exemplo, são reformulações da experiência aceitas pela comunidade científica por satisfazerem um critério de validação estabelecido por ela mesma. Este texto procura detalhar essas idéias.

Unitermos: Ciência, explicações científicas, biologia do conhecer, epistemologia.

Abstract: Unlike some epistemologists well known in science education, usually coming from the physical sciences and mostly rationalists, Maturana comes from the biological sciences and tries to explain knowing by explaining the knower and taking as starting point the observer's experience and the observation. This knower cannot distinguish, in his/her experience, between illusion and perception, but helshe can generate explanations of the experience, which are reformulations of the experience. Scientific explanations, for instance, are reformulations of experience accepted by the scientific community because they satisfy validation criteria established by the community itself. This paper attempts to clarify these ideas.

Keywords: Science, scientific explanations, biology of knowing, epistemology.

\section{Objetivo}

A finalidade deste texto, de caráter monográfico, é a de descrever idéias centrais da epistemologia de Maturana. Para aprofundamento nessa epistemologia é necessário recorrer à bibliografia indicada ao final, particularmente à obra Cognição, Ciência e Vida Cotidiana (MATURANA, 2001).

\section{Introdução}

Humberto Maturana, biólogo chileno nascido em 1928, fez doutorado em Biologia em Harvard, trabalhou em neurofisiologia no M.I.T. e é professor da Universidade do Chile desde 1960. A partir da noção de sistema, no âmbito da Biologia, Maturana se perguntou: Que classe de sistema é um ser vivo? Essa pergunta guiou suas reflexões teóricas e epistemológicas e o levou, juntamente com Francisco Varela, outro chileno com a mesma formação, ao conceito de autopoiese.

Teoria da autopoiese, ou Biologia do Conhecer, é o nome dado ao conjunto das idéias de Maturana. Autopoiese é a explicação do vivo:

É uma explicação do que é o viver e, ao mesmo tempo, uma explicação da fenomenologia observada no constante vir-a-ser dos seres vivos no domínio de sua existência. Enquanto uma reflexão sobre o conhecer, sobre o conhecimento, é uma epistemologia. Enquanto uma reflexão sobre nossa experiência com os outros na linguagem, é também uma reflexão sobre as relaçôes humanas em geral, e sobre a linguagem e a cognição em particular. (MAGRO \& PAREDES, in MATURANA, 2001, p. 13).

\footnotetext{
${ }^{1}$ Instituto de Física da UFRGS. Caixa Postal 150519, CEP 1501-970, Porto Alegre, RS.

http://www.if.ufrgs.br/-moreira. (e-mail: moreira@if.ufrgs.br)
} 
Além da Biologia, Maturana interessou-se por Filosofia, Antropologia, Anatomia, Genética e Cardiologia (estudou medicina durante quatro anos). Quer dizer, preparou-se no âmbito biológico de maneira ampla e, como conseqüência, seu interesse fundamental tem permanecido centrado no humano. Em particular, seus estudos sobre o sistema nervoso e sobre os fenômenos da percepção o levaram à conclusão de que não é o externo o que determina a experiência; o sistema nervoso funciona com correlaçôes internas (MATURANA, 2001, p. 24). Conseqüentemente, rejeita o "modo tradicional de abordar o ato cognitivo" que, segundo ele, tem sempre a ver com a indicação de algo externo ao sujeito.

Ao invés de centrar-se em características materiais dos seres vivos ou de seus componentes, Maturana (e Varela) fixa $(\mathrm{m})$ a atenção em sua organização e estrutura. A organização de alguma coisa é o conjunto de relações que devem existir ou que têm que ser satisfeitas para que essa coisa exista; refere-se às relaçôes que definem a identidade de um sistema. A estrutura refere-se aos componentes, mais as relações entre eles, que constituem um sistema particular. $\mathrm{Na}$ organização não há referência a componentes: eles têm que satisfazer as relações da organização. A estrutura tem que satisfazer as relações da organização, mas esta não faz referência aos componentes. A organização é necessariamente uma invariante. Pode haver mudanças estruturais sem perda de organização. Qualquer mudança estrutural com perda de organização é uma desintegração. (op. cit., p. 77-78). Portanto, há mudanças estruturais com conservação ou sem conservação de organização: a conservação ou não conservação é definida pelo critério de validação do observador.

No caso dos seres vivos, há, então, uma organização que os define como classe. Maturana e Varela (segundo ROSAS \& SEBASTIÁN, 2001, p. 59) propóem que o traço característico dos seres vivos é que, em sentido material, produzem a si mesmos de maneira constante e a isso chamam de organização autopoiética. Para eles, os seres vivos são máquinas autopoiéticas, ou seja, máquinas que continuamente especificam e produzem sua própria organização por meio da produção de seus próprios componentes, sob condiçóes de contínua perturbação e compensação dessas perturbações (produçãa de componentes).

A organização característica dos seres vivos é, então, a autopoiese, mas esta tem como produto a organização da máquina-ser-vivo em questão, que produz sua própria organização. Trata-se, portanto, de uma definição recursiva da organização dos seres vivos: não se trata simplesmente de uma estrutura que explica uma fenomenologia própria, mas sim de uma estrutura que determina uma estrutura que determina uma estrutura que determina uma... que explica uma fenomenologia própria. (op. cit., p. 61). Esta definição situa-se completamente na rede de relações entre relaçôes (entre relações...) que constitui a recursividade.

As máquinas autopoiéticas são autônomas (subordinam todas suas mudanças à conservação de sua própria organização), têm individualidade (mantendo invariante sua organização, conservam sua identidade) e não têm entradas nem saídas (mas podem ser perturbadas por fatos externos e experimentar mudanças internas que compensam essas perturbaçóes). (MATURANA \& VARELA, 1970/1994, apud ROSAS \& SEBASTIÁN, 2001, p. 63).

A célula é o exemplo paradigmático concreto de unidade autopoiética: seu metabolismo consiste em uma rede de interações que interconecta seus componentes moleculares e produz moléculas que formam parte da própria célula. As moléculas produzidas pela célula são produtos da dinâmica celular e ao mesmo tempo insumos para seu próprio funcionamento.

O dinamismo próprio do processo de autopoiese implica uma permanente renovação dos componentes moleculares, ou seja, uma permanente mudança estrutural. A história das mudanças estruturais de uma unidade autopoiética particular é o que Maturana chama de ontogenia (op. cit., p. 64). 
Para Maturana, existe uma congruência estrutural mínima entre o ser vivo e o meio, da qual depende a existência do primeiro. Nessa congruência, uma perturbação do meio não contém em si mesma uma especificação de seus efeitos sobre o ser vivo, é este em sua estrutura que determina sua própria mudança frente a tal perturbação. Esta propriedade das unidades autopoiéticas chama-se determinismo estrutural (MATURANA \& VARELA, 1984, apud ROSAS \& SEBASTIÁN, 2001, p. 65).

O ser vivo é, assim, uma máquina autopoiética determinada estruturalmente. A estrutura de cada ser vivo especifica quatro domínios (ibid.):

- Domínio de mudanças de estado, i. e., mudanças estruturais sem mudar a organização, mantendo, então, a identidade de classe.

- Domínio de mudanças destrutivas, i. e., mudanças desintegradoras, perdendo a organização desaparecendo como unidade de uma certa classe.

- Domínio de interações perturbadoras, ou seja, interações que geram mudanças de estado.

- Domínio de interações destrutivas, i. e., aquelas que resultam em mudanças destrutivas.

O ser vivo é, então, um sistema dinâmico (uma máquina determinada estruturalmente) e, como tal, sua estrutura está constantemente mudando, o que, por sua vez, implica constante variação nesses domínios estruturais.

O acoplamento estrutural entre duas ou mais unidades autopoiéticas de primeira ordem, mantendo a organização autopoiética, resulta em uma unidade autopoiética de segun$\mathrm{da}$ ordem e assim por diante. Para Maturana e Varela, um sistema autopoiético que implica a autopoiese das unidades autopoiéticas que o geraram, é um sistema atuopoiético de ordem superior (apud ROSAS \& SEBASTIÁN, 2001, p. 68).

Embora o objetivo deste texto seja o de descrever a epistemologia de Maturana, as referências feitas até aqui a aspectos da Biologia do Conhecer (teoria da autopoiese) são necessárias porque Maturana entende que para explicar o fenômeno do conhecer é necessário explicar aquele ser no qual se materializa esse fenômeno, ou seja, é necessário explicar o conhecedor que nesse caso é o ser humano (op. cit., p. 75). Mas para explicá-lo é necessário definir um ponto de partida e este ponto é a experiência do observador.

\section{Ilusão e percepção}

Maturana chama atenção para o fato de que, na experiência, a ilusão é indistinguível da percepção. Na vida cotidiana e na vida social, enfim, na experiência humana, não podemos distinguir entre a ilusão e o que chamamos cotidianamente de percepção (op. cit., p. 26). Por exemplo, quando "sentimos" que nosso trem está partindo, mas na verdade estamos parados e o trem no trilho ao lado é que está em movimento.

Conseqüentemente, não podemos distinguir, na experiência, entre verdade e erro: o erro é um comentário a posteriori sobre uma experiência que se vive como válida. Se não foi vivida como válida, era uma mentira. (MATURANA, 2001, p. 27). 


\section{Explicações}

Como já foi dito, para explicar o conhecer Maturana diz que é necessário explicar o conhecedor, que é o ser humano, e o caracteriza como uma máquina autopoiética, uma máquina que funciona com correlaçôes internas produzindo sua própria organização através da produção de seus próprios componentes.

Toma, então, como ponto de partida o observador observando, e o observar (ibid). Esse observador é qualquer um de nós. Quer dizer, a tarefa a qual se propõe é a de explicar o observador e o observar. Mas ele chama atenção que o explicar é uma operação distinta da experiência que se quer explicar. Ou seja, uma coisa é a experiência e outra é a explicação da experiência. Maturana dá o seguinte exemplo (op. cit., p. 28): você está dirigindo e, de repente, um carro que parece ter surgido do nada lhe ultrapassa; seu acompanhante se surpreende e você procura justificar um pouco a surpresa dizendo "certamente ele vinha muito rápido, ou estava no ponto cego do retrovisor". Mas suas palavras são uma explicação da experiência. O fato é que, na experiência, o automóvel surgiu do nada. Dizer que estava no ponto cego ou que vinha muito rápido é uma explicação da experiência.

O explicar é sempre uma reformulação da experiência que se explica. As explicaçôes são sempre reformulaçôes da experiência, mas nem toda reformulação da experiência é uma explicação. Uma explicação é uma reformulação da experiência aceita por um observador (op. cit., p. 29). O explicar e a explicação têm a ver com aquele que aceita a explicação. As explicaçōes são reformulaçōes da experiência aceitas por um observador (ibid.). No caso do ponto cego do retrovisor, essa não seria uma explicação para o aparecimento súbito do carro se não fosse aceita pelo acompanhante.

Por outro lado, a explicação se dá na linguagem. O discurso que explica algo dá-se na linguagem. Para Maturana, os seres humanos existem na linguagem. É esta nossa condição inicial (op. cit., p. 28): somos observadores no observar, no suceder do viver cotidiano na linguagem, na experiência na linguagem. Experiências que não estão na linguagem, não são. Não há modo de fazer referência a elas, nem sequer fazer referência ao fato de tê-las tido.

O explicar se dá, então, na linguagem, mas sua validade não depende do explicador e sim de quem aceita a explicação. Assim, há tantos explicares diferentes quanto modos de aceitar reformulações da experiência (op. cit., p. 30). Há tantos explicares, tantos modos de explicar, como modos de aceitar as explicações que são reformulaçôes da experiência. E isso é absolutamente cotidiano (ibid.).

Segundo Maturana, a ciência, por exemplo, se define por um modo particular de explicar. Para ele, a ciência não tem a ver com a predição, com o futuro, com fazer coisas, mas sim com o explicar. Os cientistas são pessoas que têm prazer em explicar. O que define o cientista , em sua ação como cientista, é o modo de explicar e o critério de aceitação de explicaçōes que usa (ibid.). Assim sendo, não tem sentido separar a ciência da vida cotidiana. Para Maturana, a ciência é uma glorificação da vida cotidiana, na qual os cientistas são pessoas que têm a paixão de explicar e que estão, cuidadosamente, sendo impecáveis em explicar somente de uma maneira, usando um só critério de validação de suas explicaçôes... (op. cit., p. 31).

\section{Dois modos de aceitar explicações (reformulações da experiência)}

Para Maturana, há dois modos fundamentais de aceitar reformulações da experiência (op. cit., p. 32 e 33):

No primeiro deles, o observador comporta-se como possuidor de certas habilidades cognitivas como se elas fossem constitutivas dele. Assume-se o observador e o observar como 
condições iniciais constitutivas. Conseqüentemente, a pessoa opera como se os elementos que usa no observar, no explicar, no escutar, existissem independentes dela mesma. Seres, objetos, idéias, diferentes modos de aceitar, existem independentemente do que a pessoa faz como observador. A existência é independente do observador. Este caminho explicativo é o que Maturana (p. 32) chama de caminho da objetividade. Objetividade a seco, ou objetividade sem parênteses, como diz ele. Nesse caminho, assume-se, explícita ou implicitamente, que é possível distinguir entre ilusão e percepção porque se admite referência a algo independente do observador. Percebe-se, vê-se, detecta-se com instrumentos; a razão permite dizer que isto é assim independentemente do observador.

No segundo caminho, aceita-se a pergunta pelo observador, assume-se a biologia do conhecer e, nesse caso, tal independência não existe. Assume-se o fato de que o observador não pode distinguir entre ilusão e percepção. $\mathrm{O}$ fenômeno do conhecer tem que ser explicado sem a suposição de que é possível distinguir entre ilusão e percepção. O que está disponível para explicar o conhecer é o que o observador faz no observar, i. e., o que ele faz como observador. A existência depende, então, do observador e a isso Maturana (p. 34) chama de objetividade entre parênteses. Como ser humano, como ser vivo, o observador não pode distinguir entre ilusão e percepção, logo, qualquer afirmação cognitiva sua é válida no contexto das coerências que a constituem como válida.

\section{Realidade}

No caminho explicativo da objetividade sem parênteses, há uma realidade independente do observador, à qual ele tem um acesso privilegiado que lhe serve para elaborar sua explicação e configurar afirmações cognitivas como petições de obediência (p. 36), ou seja "é assim", "é independente de mim" ou "de ti", portanto, deve ser aceita.

Porém, no outro caminho, o da objetividade entre parênteses, uma afirmação cognitiva é válida apenas no contexto das coerências que a constituem como válida. O observador não pode pretender um acesso privilegiado no explicar pois, como ser humano, como ser vivo, não pode distinguir entre ilusão e percepção. (ibid.) Nesse caminho há muitas realidades. A realidade no caminho da objetividade entre parênteses é uma proposição explicativa. Ou seja, é sempre um argumento explicativo. Então, há tantas realidades - todas diferentes, mas igualmente legitimas - quantos domínios de coerências operacionais explicativas, quantos modos de reformular a experiência, quantos dominios cognitivos pudermos trazer à mão (p. 38). Se há discordância entre o explicador e outra pessoa é porque essa outra pessoa está em um domínio de realidade diferente daquele do observador, porém igualmente legítimo. Isso significa que as distintas realidades que aparecem nesse caminho não são visões distintas da mesma realidade. Não! Há diferentes realidades, todas legítimas, o que para Maturana (p. 37), não é o mesmo que dizer que a realidade não existe.

No caminho explicativo de objetividade sem parênteses o explicador não é responsável pela validade do que diz porque a realidade é independente dele. Portanto, a negação do outro é responsabilidade desse outro. O outro nega a si mesmo (p. 38). Porém, no caminho explicativo da objetividade entre parênteses o outro pode estar em um domínio de realidade diferente daquele do explicador que é igualmente válido, ainda que não lhe agrade. $\mathrm{O}$ outro pode, então, ser negado não porque esteja equivocado mas porque está em um domínio de realidade que não agrada ao primeiro. Pode também haver aceitação e respeito ao domínio de realidade do outro. Respeito, não tolerância, porque esta implica negação do outro enquanto o primeiro implica em se fazer responsável pelas emoções frente ao outro, sem negá-lo (p. 39). 


\section{Emoções}

Emoções são disposiçōes corporais dinâmicas que especificam os domínios de ações nos quais os animais, em geral, e os seres humanos, em particular, operam em um dado instante. (p. 129). Maturana chama de açôes tudo o que fazemos em qualquer domínio operacional que geramos em nosso discurso, por mais abstrato que ele possa parecer. Assim, pensar é agir no dominio do pensar, refletir é agir no domínio do refletir, falar é agir no dominio do falar, e assim por diante, e explicar cientificamente é agir no dominio do explicar cientifico (p. 128).

$\mathrm{Na}$ vida cotidiana, nos movemos de um caminho explicativo para outro em uma dinâmica de emoções. Muitas vezes aceitamos e respeitamos o outro (estamos no caminho explicativo da objetividade entre parênteses), mas freqüentemente queremos que o outro faça o que queremos, ou que aceite o que explicamos e, então, recorremos à razão, nos colocando no caminho da objetividade sem parênteses. Argumentamos que o outro tem que fazer o que queremos ou estar de acordo com o que dizemos porque é "racional e objetivo" (p. 39).

Os cientistas, por outro lado, afirmam que suas emoçôes não participam na geração das explicaçōes científicas porque o critério de validação dessas explicaçōes especifica, de uma forma independente de seu emocionar, quais as operações que devem efetuar como observadores-padrão para gerar tais explicaçôes, e porque aprenderam a serem cuidadosos para não deixar suas preferências e desejos distorcerem-se e, com isso, invalidarem sua aplicação do critério de validação das explicações científicas (p. 145). Afirmam também que aprendem a reconhecer que quando isso acontece cometem um erro grave.

Mas para Maturana as emoçôes especificam a todo momento o domínio de açôes no qual os cientistas operam ao gerarem suas perguntas. Quer dizer, as emoções não entram na validação das explicaçôes científicas, mas o que é explicado surge através do seu emocionar explicando o que querem explicar, e o explicam cientificamente porque gostam de explicar dessa maneira. (p. 147)

Então, a ciência, como um dominio cognitivo, existe e se desenvolve como tal sempre expressando os interesses, desejos, ambiçôes, aspiraçôes e fantasias dos cientistas, apesar de suas alegaçōes de objetividade e independência emocional (ibid.)

Os cientistas, portanto, praticam a ciência como uma maneira de viver sob uma das numerosas emoçôes que constituem o ser humano em seu viver como ser humano emocional normal, ou seja, sob a paixão, emoção, desejo do explicar. (p. 150).

A objetividade e a universalidade da ciência são, para Maturana, afirmaçōes morais. A afirmação de objetividade na prática da ciência é uma afirmação moral porque significa o comprometimento do observador-padrão em não deixar seus desejos ou preferências distorcerem ou interferirem na sua aplicação do critério de validação das explicações científicas. Analogamente, a alegação de universalidade da ciência é uma alegação moral porque uma vez que a ciência, como domínio cognitivo, acontece na práxis de viver do observador-padrão como ser humano, todo ser humano pode, em princípio, operar como observador-padrão, isto é, aplicar, objetivamente, o critério de validação das explicaçôes científicas, se assim o desejar (p. 148). Ou seja, a universalidade da ciência não está em sua referência a um universo, mas está na configuração de uma comunidade humana que aceita o critério explicativo da ciência (p. 60). 


\section{Ciência}

O cientista faz ciência como observador, explicando o que observa. Como obsevador é ser humano e este já se encontra na situação de observador observando quando começa a observar seu observar na sua tentativa de descrever e explicar o que quer explicar. Quer dizer, ele já se encontra na linguagem, fazendo distinções na linguagem quando começa a refletir na linguagem sobre o que faz para explicar o que quer explicar. Isso é cotidiano. O cientista já está na experiência de observar quando começa a observar o que quer observar para explicar o que quer explicar.

Mas, se o cientista faz o que faz o observador cotidiano que vive no observar, o que caracteriza a ciência como domínio cognitivo e o cientista como cientista operando na paixão do explicar aquilo que deseja explicar?

É a aceitabilidade de um critério particular de validação das explicações (científicas). As explicaçôes científicas não se referem à verdade, mas configuram um dominio de verdade. A ciência é um dominio cognitivo válido para todos aqueles que aceitam o critério de validação das explicaçôes cientíticas (p. 57).

Para Maturana, a ciência é, então, uma atividade humana, cotidiana. O que a define como um dominio explicativo particular é o critério de validação de explicações que os cientistas usam, e o que define o cientista como um tipo particular de pessoa sob a paixão do explicar é o uso do critério de validação de explicações que constitui a ciência como um dominio explicativo (p. 134).

\section{O critério de validação das explicações científicas}

São quatro as condições que devem satisfazer as explicações de um fenômeno (reformulações da experiência) para serem consideradas científicas, na perspectiva de Maturana (p. 56, $57,134,135,138,139,140)$ :

1. Ter o fenômeno a explicar, o qual é sempre apresentado como uma receita do que um observador deve fazer para ter a experiência que vai tratar como fenômeno a explicar. Fazer tal e tal coisa, ver isso e aquilo, medir assim e assim, controlar de tal maneira,... Ou seja, a primeira condição é a apresentação da experiência (o fenômeno) a ser explicada em termos daquilo que o observador-padrão deve fazer em seu domínio de experiências para experienciá-la. Assim, é o que o observador tem como experiência que constitui o que se quer explicar, não o fenômeno. Aqueles que não podem satisfazer as condições que geram a experiência não têm lugar no espaço de atividades do cientista.

2. Ter a hipótese explicativa, que é sempre a proposição de um mecanismo que, posto a funcionar, gera o fenômeno a explicar como resultado deste funcionamento na experiência do observador. Em outras palavras, a reformulação da experiência (o fenômeno) a ser explicada dada sob a forma de um mecanismo gerativo que, se realizado por um observador-padrão lhe permite ter em seu domínio de experiências a experiência a ser explicada, tal como apresentada na primeira condição.

3. Satisfazer a dedução, a partir da operação do mecanismo gerativo proposto na segunda condição, assim como de todas as coerências operacionais do âmbito de experiências do observador-padrão a ele vinculado, de outras experiências que um observador-padrão deveria ter através da aplicação daquelas coerências operacionais e das operações que deve realizar em seu domínio de experiências para tê-las. 
4. A realização dessas experiências, ou seja, a experiência, por um observador padrão, das experiências (fenômenos) deduzidos na terceira condição através da realização, em seu domínio de experiências, das operações também deduzidas nessa condição.

É apenas quando essas quatro condições são conjuntamente satisfeitas que uma explicação pode ser considerada científica. Isto é, quando isso acontece, o mecanismo gerativo proposto na segunda condição passa a ser uma explicação científica.

Maturana chama à atenção que esse critério de validação das explicações científicas não requer a suposição de uma realidade independente - em nenhuma das condições se faz essa suposição. Ela pode ser feita, mas é supérflua para uma explicação ser científica.

Os cientistas, segundo ele, procuram ser impecáveis em satisfazer essas quatro condições de uma maneira coerente, sem saltos de um domínio para outro, porque no momento em que isso acontecer e a dedução não for feita a partir das coerências operacionais ela não serve. (p. 57)

Uma explicação é válida na comunidade de cientistas enquanto observadores-padrão aceitam que o critério de validação das explicações científicas foi satisfeito. (p. 136).

$\mathrm{Na}$ vida cotidiana, o ser humano também explica, através de reformulaçôes da experiência, que a maneira pela qual nós validamos nossas ações na vida cotidiana, dentro de qualquer domínio operacional, envolve as mesmas coerências operacionais envolvidas no critério de validação das explicações científicas. (p. 139). A diferença entre nossa operação na vida cotidiana como cientistas e como não-cientistas depende de nossas diferentes emoçōes, de nossos diferentes desejos de consistência e impecabilidade em nossas açôes e de nossos diferentes desejos de reflexão sobre o que fazemos (ibid.). Como cientistas estamos sob a paixão do explicar, e toda dúvida, toda pergunta, é sempre bem-vinda para nossa realização enquanto tal. Como não-cientistas, não somos cuidadosos, usamos sucessivamente muitos critérios deferentes de validação de nossas explicações, mudamos freqüentemente de domínios fenomênicos em nosso discurso. (p. 140)

O que torna científica uma explicação ou uma teoria é o fato de ela ser validada pelo critério de validação das explicaçôes científicas, não a quantificação ou a possibilidade de algumas predições (p. 142), ou a falseabilidade e verificabilidade:
As noçôes de falseabilidade, verificabilidade ou confirmação aplicar-se-iam à validação do conhe- cimento cientifico apenas se este fosse um dominio cognitivo que revelasse, direta ou indiretamen- te, por denotação ou conotação, uma realidade transcendente independente do que o observador faz, e se a segunda condição do critério de validação das explicações científicas fosse um modelo dessa realidade transcendente, em vez de um mecanismo gerativo que faz surgir a experiência a ser explicada tal como é apresentada na primeira condição. (p. 143)

Para Maturana, uma teoria é um sistema explicativo que correlaciona muitos fenômenos (experiência) de outra forma aparentemente não correlacionados. É um sistema proposto como um domínio de explicaçôes coerentes, junto a alguns conceitos que definem a natureza de sua conectividade interna e a extensão de sua aplicabilidade gerativa. (p. 163). Para ele, o objetivo de uma teoria científica é explicar, e não resguardar ou proteger qualquer princípio ou valor, ou obter qualquer resultado desejado. (p. 166). Devido ao seu modo de constituição, as teorias científicas surgem intrinsecamente em um dominio aberto de reflexóes sobre tudo, incluindo seus fundamentos, e são, operacionalmente, livres de qualquer dogmatismo (p. 167). (Teorias filosóficas, por outro lado, estariam comprometidas com a manutenção de princípios explicativos. Elas surgem no processo de gerar um sistema logicamente consistente e diretamente subordinado à conservação de algumas noçôes explicativas básicas, sob a forma de princípios ou valores; ibid.) A prática científica é, em princípio, libertadora. 
Finalmente, há que registrar que para Maturana as noções de progresso, de responsabilidade social e ética não se aplicam à ciência como domínio cognitivo. Tais noções aplicam-se às açôes humanas, não à ciência. A noção de progresso tem a ver com o que nós, seres humanos, consideramos melhor ou desejamos que aconteça na vida humana. A noção de responsabilidade social tem a ver com nossa consciência de querermos ou não as conseqüências de nossas ações. E a noção de ética tem a ver com nosso interesse pelas conseqüências de nossas ações na vida de outros seres humanos. (p. 149-150). O conhecimento científico pode ser usado para qualquer propósito que possamos querer e aí entram, no fluir de nosso linguajar e emocionar, as noções de progresso, responsabilidade e ética.

\section{Conclusão}

Nesta monografia tentei descrever idéias centrais da epistemologia de Maturana. Para isso, tive que começar com a teoria da autopoiese, que é a explicação do ser vivo, pois o observador-padrão é um sistema vivo estruturalmente determinado e, enquanto tal, não tem como fazer, operacionalmente, uma distinção que se possa, de alguma forma, afirmar ser a distinção de algo independente de seu fazer. Esse observador-padrão não pode distinguir, na experiência, entre ilusão e percepção. Mas pode gerar explicações da experiência que são reformulações da mesma. Toda explicação é uma reformulação da experiência aceita por outro, segundo algum critério de validação. As explicações científicas são reformulações da experiência aceitas pela comunidade científica com base em um critério claro de validação estabelecido por ela mesma. Cotidianamente também explicamos, mas nossos critérios de validação não são rigorosos, consensuados, únicos.

Maturana é, ou foi, cientista na área da Biologia; fez seu doutorado em Biologia em Harvard e trabalhou no M.I.T., duas instituições mundialmente reconhecidas na pesquisa científica. Mas sua epistemologia é diferente da de outros cientistas porque seu ponto de partida é o observador-padrão enquanto ser vivo. Quer dizer, o ponto de partida é distinto e dele decorre, inevitavelmente, uma epistemologia distinta. Se consegui descrevê-la, neste trabalho, sem grandes distorções, ou omissões, não sei, mas, como diria Maturana, o fiz na emoção, na paixão, de descrever.

\section{Referências}

MATURANA, H. Cognição, ciência e vida cotidiana. Belo Horizonte: Editora da UFMG, 2001. 200 p.

ROSAS, R. Y. \& SEBASTIÁN, C. Piaget, Vigotski y Maturana: constructivismo a tres voces. Buenos Aires: Aique, 2001.

\section{Bibliografia adicional sugerida}

MATURANA, H. R. La realidad ¿objetiva o construida?: I fundamentos biológicos de la realidad. México: Anthoropos, 1995.

. La realidad ¿objetiva o construida? II fundamentos biológicos del conocimiento. México: Anthoropos, 1996.

. A ontologia da realidade. Belo Horizonte: Editora da UFMG, 2001. 350 p. 
MATURANA, H. R. \& VARELA, F. El árbol del conocimiento: las bases biológicas del conocimiento humano. Madrid: Debate, 1996.

. A árvore do conhecimento: as bases biológicas da compreensão humana. São Paulo: Palas Athena, 2001. 283 p.

VARELA, F. Conocer. Barcelona: Gedisa, 1998.

VARELA, F. J.; THOMSON, E.; ROSCH, E. The embodied mind: cognitive science and human experience. Cambridge: The MIT Press, 1993. 308 p. 